\title{
Three Premodern Concepts of Disease
}

\author{
Marija Raguž ${ }^{1}$, Tamara Alebićn \\ ${ }^{1}$ Faculty of Medicine, University of Osijek, Croatia \\ ${ }^{2}$ Faculty of Dental Medicine and Health, University of Osijek, Croatia
}

\begin{abstract}
A B S T R A C T
The concepts of health and disease have an impact on the efficiency of the medical system. Currently, there are no unanimously accepted definitions of health and disease, despite the fact that many investigations have attempted to capture their essence. Most of the available research about the concept of disease relies on the evidence-based disease concept of the modern medicine. That concept differs from the lay concept of disease or illness. In this research we use the cognitive linguistic approach to concepts, taking into consideration the way in which human mind processes the surrounding reality. Those processes are based on the universal principles because of the embodiment of cognition. Consequently, concepts are to some extent independent of time and culture. We have selected three premodern sources with sufficient information about disease to ascertain whether they have similarities in the comprehension of the disease. The first source is "Huangdi Neijing" "Suwen" part, from Chinese ancient medicine, the second one is "Hippocratic Corpus" from ancient Greece, and the third is "Otok" by Josip Lovretic from 19th century eastern Croatia. They are products of very different cultures and historical periods. Conducting comparison of features related to disease in the three sources, we have recognized that body, change, process and control are related to the common shared attributes critical for the concept of disease.
\end{abstract}

Key words: medical anthropology, history of medicine, concept formation, disease characteristics, cross-cultural comparison, ancient history medicine

\section{Introduction}

Cognitive linguistic changed the paradigm of the human conceptual system. It introduced the idea of embodied cognition in $1975^{1}$. Embodiment of the human cognition hypothesizes that the human thought is affected by the human body; it is physical1,2. Cognitive linguists and neuroscientists investigate the nature of the connection between the mind and the body, but also the influence that the reality has on the human conceptual system ${ }^{1,3-5}$. The ideas developed by cognitive science imply that reality is constructed in the human mind through cognitive concepts based on bodily experience ${ }^{3}$. If that is so, then cognitive concepts are universal to all humans because humans are defined as a species by their common physical constitution - the body. That is the basis for the topic of this text which aims to investigate the concept of disease in the sources that are not influenced by the modern medicine. The question is whether it is possible to recognize features essential to disease as a concept that is not conditioned by a specific culture or a time period, but is universal instead.
Importance of concepts in medicine

Concepts in general affect human behaviour ${ }^{3}$. Health and disease are both such cognitive concepts. In order to start treating a disease, both medical professionals and the patients must recognize the existence of a disease, which is why it is important to know what a disease is. According to Campbell and his colleagues, there are differences between the professional and lay concept of the disease in the sense that medical professionals are more likely to consider an entity a disease than laypeople do ${ }^{6}$. Knowledge, also organized through concepts, is in a positive relationship with patient adherence ${ }^{7,8}$. Modern medicine is very successful in treating diseases, but it is noted that patient compliance has a significant influence on the effectiveness of medicine ${ }^{9-11}$, and that patient compliance is under influence of different factors, such as knowledge, attitudes, individual's health beliefs, personality traits, culture and language ${ }^{7,8,12-14}$. Medical anthropology recognizes culturally conditioned differences between the provider and recipient of medical care that diminish the success of modern medicine in some societies and

Received for publication April 11, 2021 
anthropologists help overcome the problematic cultural gap $^{15-17}$. Discovering potentiallly universal features of the concept of disease could be of use in such situations. An example of use of a metaphor is the SOCIETY IS AN ORGANISM in Andrija Štampar's public health campaigns ${ }^{18}$.

Concepts are also important for medical science. New concepts enable new discoveries. It is possible to illustrate it with an example from the history of medicine: William Harvey's new theory of blood circulation which changed the views on the physiology, disease and therapy. ${ }^{19,20}$ It was possible to see the circulatory system before Harvey's time, but he was the first one who conceptualized it as a closed, circulatory system. That idea enabled some later discoveries such as transfusions, injections and infusions ${ }^{20}$ That is an example of the manner in which conceptualizing the body influences medical science and therapy. However, there are also more abstract scientific concepts. An example is Claude Bernard's milieu intérieur, later homeostasis, further clarified by Walter Cannon, and still considered to be one of the core concepts of physiology ${ }^{21,22}$.

\section{Concept of disease in previous research}

Bernard's ideas also led to the conceptualization of disease as a dynamic process between a noxic agent and the response of the body, as opposed to the prior view of disease as a patho-anatomical concept ${ }^{23}$. That fact contributed to a better understanding of the disease as a physiological process, and became one of the forerunning ideas to the biomedical model of disease, which constitutes of etiology, pathology and manifestation ${ }^{24}$. That is what disease is considered to be in modern biomedicine and in the English language. It occupied the word 'disease' in English, and defined it through the opposition with 'illness' ${ }^{25-27}$. Disease and illness are scientific concepts which were separated as a part of long tradition in medicine, and with little consideration for the sufferer, much more to the disease itself, as Minaire observes ${ }^{24}$. An illness becomes a disease when medicine confirms it is a disease. Signs have priority over symptoms when determining what disease is according to biomedical model. That is in line with the evidence-basedness of the modern medicine.

However, medicine is not only a science, it is also an art of healing. Medical anthropology recognizes medical systems in which it considers medical professionals and laypeople as subjects of equal importance and medical science as a tool, not an end in itself ${ }^{28,29}$. Science and its application through treatment are intertwined, disease - as a part of the scientific domain in medicine, and illness - as a part of medicine in practice, are overlapping. They are not strictly separated, although there is a tendency to separate them, as was previously mentioned ${ }^{24}$. They are defined through mutual opposition, but such a definition just stresses a single feature - the distinction between them, more accurately - the aspect from which they are viewed. It puts aside everything that they have in common. It is important to be aware of the concept itself. Cognitive linguistics has introduced new categories which have fuzzy boundaries and which are based on family resemblance as defined by Wittgenstein ${ }^{2,30}$. It is an important step away from the traditional binary categories with firmly defined members and non-members, whereas cognitive categories have a gradience of shared attributes $^{30}$. A member of one category can also be a member of another category, and such is the case of the members of the categories 'illness' and 'disease'.

Separation of categories of illness and disease reflects itself into the reality. It is normal for people to search help both from modern medicine, as well as alternative medical systems for the same health issue ${ }^{31,32}$. It was previously mentioned that medical anthropologists sometimes help in introducing new treatments into certain communities. There are communities in which there are parallel medical systems, for instance in Africa ${ }^{31}$. People use modern medicine, but they still possess a traditional view of health and disease, so they also see diviners orhealers with a more holistic approach to their well-being ${ }^{31}$. Modern medicine thinks of itself as timeless truth, regards itself universal and free of any cultural conditioning, which anthropologists refer to as 'Culture of No Culture' ${ }^{33}$. However, medical systems include people and contexts and they are therefore culturally conditioned. It is only the science, as a part of the modern medical system, that deals with facts and evidence and can therefore be considered independent of culture. The expression 'Culture of No Culture' can be perceived as a consequence of the personification of medicine in practice with medicine as a science, in our opinion.

The same reflects on the examination of the concept of disease. Studies of disease as a concept mostly have a starting point in the modern medical science, which considers biological dysfunction as the necessary or sufficient condition for disease ${ }^{34}$. Disease and health as concepts (health inevitably connected to disease as a concept) were investigated by psychologists ${ }^{6,35}$, philosophers of medicine, experts in social medicine and public health ${ }^{25-27,34,36-41}$. Hodgkin presented a few metaphors important in medicine in 1985, and it was under the influence of Lakoff whose work he referenced. He recognized metaphors: DISEASE IS AN OBJECT (rather than a process), HEALTH IS UP, ILLNESS IS DOWN, BODY IS A CONTAINER FOR DISEASE, BODY IS A MACHINE, MEDICINE IS WAR, MEDICINE IS A DETECTIVE STORY, and a lay metaphor ILLNESS IS IMBALANCE ${ }^{42}$. He did not pursue with such work, and to our knowledge, his work did not have a great impact.

It does not matter whether they are medical professionals or human scientists, they analyze the concept of disease in line with the modern medicine, and from the viewpoint of medical science. If we analyze the way disease is presented in a student textbook of internal medicine, which is based on the medical science, it is a cluster of signs and symptoms which reoccur together and they become a recognizable entity - a specific disease ${ }^{43}$. World Health Organization has a disease classification ${ }^{44}$ and a definition of health ${ }^{45}$ New York, 19 June - 22 July 1946; signed on 22 July 1946 by the representatives of 61 States (Official Records of WHO, no. 2, p. 100, but it does not 
have a definition of disease. There are recognizable categories of diseases in that classification, for instance diseases of the immune system and endocrine, nutritional or metabolic diseases ${ }^{44}$. That would correspond with basic-level terms in cognitive linguistics ${ }^{30}$. However, except for the disease, the WHO classification also includes conditions, disorders, factors, for example ${ }^{44}$. That suggests that the disease classification is not complete if it only encompasses diseases. It is also necessary to point out that disease as a concept is, even in the biomedical sense, a dynamic category. It keeps changing because of novel diseases and new scientific discoveries.

Modern medical science does indeed have a clear vision of what disease is. It is an entity comprised of signs and symptoms, a biological dysfunction. However, that does not correspond with the applied medicine and it does not always satisfy those who carry the diseases, as it is obvious from the communities in which people turn to traditional medicine along with the biomedicine ${ }^{31,32,46}$. As opposed to asking what modern medical science categorizes as disease, or asking what disease is at all, the question we ask is what did people think disease was when they were not influenced by modern medicine.

\section{Sources and Methods}

Three sources were used for the analysis: Inner Canon of the Yellow Emperor (Huangdi Neijing), Hippocratic Corpus and Otok by Josip Lovretić. They were chosen because they belong to different historical periods and different cultures. The only thing they do have in common is that they provide sufficient data about diseases and it is possible to hypothesize about the concept of disease in these works. The other important aspect is the language Huangdi Neijing is originally written in Chinese which belongs to a different major language family (Sino-Tibetan) than the languages of the other two sources (Indo-European). Of all the sources we considered for analysis, these three were chosen because they cover the longest time range - since Huangdi Neijing is one the oldest sources about medicine (but not Indo-European as Sushruta Samhita, for example). They provided the maximal number of differences that we could find in just three sources, when it comes to the time period, culture, language and authors.

The oldest one is the Inner Canon of the Yellow Emperor (Huangdi Neijing). It belongs to Chinese traditional medicine and it was the most influental writing of that medical system ${ }^{47}$. It is comprised of two parts: the Basic Questions (Suwen) and the Divine Pivot (Lingshu). The Inner Canon was compiled through a long period of time, over several centuries ${ }^{47}$. According to some, it was written during the period of $475-225 \mathrm{BCE}^{48}$. We only analyzed the part Suwen using the English translation by Ilza Veith ${ }^{49}$.

The second one is the Hippocratic Corpus. It is comprised out of fifty to seventy essays ${ }^{50}$, representing the core set of medical teachings in ancient Greece ${ }^{51}$. They were named after Hippocrates, a famous Greek physician who was born in $460 \mathrm{BCE}^{52,53}$. Most scholars agree that the Hippocratic Corpus was compiled several centuries later ${ }^{53}$. However, it is authorative and worthy of study, according to Magner ${ }^{50}$. We analyzed it using the version translated by Francis Adams ${ }^{54}$.

Huangdi Neijing and Hippocratic Corpus were written by medical professionals of their time and the third one is a monograph Otok, written by a Croatian priest in $19^{\text {th }}$ century $^{55}$. It was originally published sequentially by the Yugoslav Academy of Science and Arts from 1897 to $1918^{55}$. Lovretić was a priest but he proved to be a very skillful ethnographer ${ }^{56}$. This source belongs to the time when medicine was already modern in the sense that it was evidence-based, and experimental ${ }^{23}$. The locals in Otok were exposed to the medicine of that time. Otok in contemporary Croatian region Slavonia was a part of Austria-Hungary at that time, and under jurisdiction of the public health law from $1874{ }^{57}$. However, Lovretic wrote himself that the locals were not inclined to see the doctor if they did not have to ${ }^{55}$. Lovretic named diseases recognized by his local community, he used locals as informants and he presented their view of disease.

The sources are structured in different ways. Huangdi Neijing is in a form of a conversation about health, diseases, causes of diseases, treatment and well-being in gener$\mathrm{al}^{49}$. Hippocratic Corpus consists of essays on different subjects. There are descriptions of symptoms, life conditions in connection to diseases, ancient medicine, healing and other ${ }^{54}$. Otok consists of descriptions organized in chapters. A few chapters mention diseases: Body constitution [Tjelesni ustroj], Necessities of life [Životne potrepštine] and Customs [Običaji] ${ }^{55}$. Diseases are named and they mostly have a brief description; some through symptoms, some through causes and consequences.

We approached each of these sources individually and analyzed what was classified as disease in each of them. The focus is on 'disease' as a concept and the shared attributes connected to disease through conceptual metaphors and especially metonymies. Those are used in this article as described by Panther and Thornburg, as mental skills of analogical and associative thinking, figures of thought58. Lakoff defined metonymy as a major source for prototype effect ${ }^{59}$. The concept of the disease might be a prototype category as Sadegh-Zadeh claims ${ }^{60,61}$. Even if it reflects the prototype effect, it is still a question whether it is what Lakoff recognizes a cluster of cognitive models (like the category 'mother') or what he calls a feature bundle, for instance ${ }^{59}$. The type of the cognitive model of the 'disease' category is not in the focus here, but the question - what did an entity have that made it a part of that category. This research is trying to uncover what we believe already exists: a universal, prescientific concept of disease that belongs to general population, not exclusively to medical science. It is not usual to analyze concepts through translations. However this research aims to discover what is universal in the investigated concept under the assumption that there is a common core which is not conditioned 
by culture or language, and that is only accessible through cross-cultural comparison.

\section{Analysis of the Sources}

The question we asked was - what is recognized as disease? What is perceived as disease-related? What was considered important enough in relation to disease to be mentioned in the analyzed sources? Everything recognized in the sources as disease-related was considered to be a shared attribute matched to the cognitive model 'disease'. It is not a question here what people said that disease is, the question is what they thought; which segments of reality did they connect with the concept 'disease'? That is the first step and the focus of this research. This is not an analysis of cognitive models and it is not an analysis of words or phrases. It is an attempt to clarify in which way reality, related to the concept 'disease', was reflected in the human mind prior to modern medicine.

\section{Huangdi Neijing}

Chinese concept of disease is based on balance. Tao is balance. To be healthy means to be in the balance, close to Tao. The path to Tao is moderation, temperance, balance of Yin and Yang. According to that: HEALTH IS TAO, HEALTH IS BALANCE, HEALTH IS MODERATION, DISEASE IS AN EXCESS OF YIN, DISEASE IS AN EXCESS OF YANG.

Disease in Su Wen is defined through its causation and through its characteristics; therefore DISEASE IS A CONSEQUENCE OF A PARTICULAR BEHAVIOR (as a metonymic model EFFECT FOR CAUSE) and DISEASE IS A PHYSICAL PROCESS.

When it comes to the disease as a physical process, it is a process recognized through symptoms. DISEASE IS A SYMPTOM is the conceptual metonymy used in all the sources.

DISEASE IS AGING - it encompasses skin changes, losing sexual features (menstruation, impotence), losing hair, occuring of the wrinkles, poor posture, losing teeth, weakness, losing moisture ${ }^{49}$.

There is an emphasis on losing, AGING IS A LOSS < DISEASE IS A LOSS. There are other features of disease connected to loss: paralysis, as a loss of movement. Other examples are the ears turn deaf; reduced life energy; the eye becomes blinded ${ }^{49}$.

Many symptoms are certain physical acts, DISEASE IS A SYMPTOM > SYMPTOM IS AN ACTION namely: cough; diarrhoea; convulsion; troubled breathing; change in pulse; belching; throbbing of the heart; paralysis; vomiting; chattering; sneezing; running at the nose; madness; talking wildly and incoherently; the tongue curls up and becomes spongy and porous and shrinks towards the upper gum; ${ }^{49}$. All of them have a common feature that they are not controled, they are unexpected, so it can be said that DISEASE IS AN INVOLUNTARY ACT.
Disease is felt by the sick person, DISEASE IS A SENSATION > DISEASE IS PAIN/ACHE: head ache, back ache, bones ache, eyes ache, pain within the body, pain while swallowing, pain in the legs, pain within the stomach, pain within the breast extending over the branches of the ribs, pains within both arms, ${ }^{49}$.

Disease is visible as a change on a person. DISEASE IS CHANGE. It can be a change in complexion, there can be a change of color or humidity of the skin (DISEASE IS A CHANGE IN THE COMPLEXION). Complexion can become black, yellow, green or red $^{49}$, and also it is a sign of disease when skin becomes withered; At first his complexion turns green, later it turns white and then death follow ${ }^{49}$.

There can also be manifestations of DISEASE AS A CHANGE IN BEHAVIOR: but then the patient gets frightened and begins to talk wildly and incoherently; The spirit becomes easily provoked and annoyed, and the thoughts devoid of joy ${ }^{49}$.

Another change pointing at disease is recognized as DISEASE IS A CHANGE IN BREATHING: shortness of breath; panting and exhausted; Breath does not go in and come out ${ }^{49}$.

One of the most important signifiers of disease in traditional Chinese medicine is the pulse. Feeling the pulse, sphygmology, was the most powerful diagnostic weapon in that medical system ${ }^{50,52}$. Some examples of changing pulse qualities are: pulse hardens lower pulse being empty and slow and the upper pulse being quick and full the pulse has a red appearance the pulse has a white appearance ${ }^{49}$. It is without a doubt that DISEASE IS A CHANGE OF PULSE in Chinese medicine, for every disease.

Disturbance in fluids can refer to leakage (DISEASE IS LEAKAGE/DISEASE IS LOSS OF FLUIDS): tears, sores, running nose, bleeding, sweat before death, urine and stool which are secreted contain pus and blood, copious urination, inability to retain food ${ }^{49}$. On the other hand, the retention of fluids is also bad (DISEASE IS RETENTION OF FLUIDS): urine retention, swellings and so on.

DISEASE IS LOSING STRENGTH: weakness, exhaustion, deficient in strength. Connected to that, DISEASE IS NUMBNESS. Every major organ can become numb, so there are: numbness of the liver, numbness of the bones, numbness in the hands, numbness of the heart, numbness of the lungs, numbness of the kidneys ${ }^{49}$.

Disease can also have death as the final symptom, DISEASE IS DEATH/DISEASE IS LOSS OF LIFE. their resulting diseases are difficult to cure and within a period not exceeding one year those afflicted will most certainly die; Life is interrupted, sweat appears and when it is all spent death follows; At first his complexion turns green, later it turns white and then death follows ${ }^{49}$.

Disease as a physical process and the causation of disease can both be described by the metaphor DISEASE IS IMBALANCE. There are two axis: hot and cold and dry and moist, which belong both to symptoms and causes. The five evils that can befall the viscera are: heat is inju- 
rious to the heart; cold is injurious to the lungs; winds are injurious to the liver; moisture is injurious to the spleen; and excessive dryness is injurious to the kidneys ${ }^{49}$. Too much cold/heat or moist/dampness can cause a disease, and also when the body is too cold/hot/wet/dry is a symptom of an illness, DISEASE IS HOT: Fish causes people to burn within (thirst); there is heat within the throat; the body is hot and feverish and there is no perspiration ${ }^{49}$. DISEASE IS COLD: external evidences are chills and fevers, disease is contracted through chills and dampness; The extreme cold causes many diseases; When there is an excess of Yin there is too much perspiration and colds and chills ${ }^{49}$. DISEASE IS DRY: skin becomes withered the finger and toe nails wither and decay blood then coagulates within the flesh disease is contracted through chills and dampness; Fish causes people to burn within (thirst) ${ }^{49}$. DISEASE IS WET blood in sputum, sweat, tears; urine and stool which are secreted contain pus and blood ${ }^{49}$.

Imbalance can refer to other possible causes of diseases. DISEASE IS OVERINDULGENCE in food: too much food of a certain taste can cause a disease (pungent, salty, bitter). Also, overindulging in passion can cause disease. Imbalance in emotions is symptomatic: emotion of anger arises from the fullness of the liver. The emotion of sympathy arises from the fullness of the lungs. The emotion of fear releases the impulses of the spleen. The feeling of worry releases the impulses of the heart ${ }^{49}$.

Along with the hot and cold and dry and wet, the wind can also be at the same time the cause and the symptom (the heart is filled with vapors) of a disease. Especially the „evil air"can be the cause of disease. DISEASE IS WIND: The east wind arises in Spring; its sickness is located in the liver and there are disturbances in the throat and neck. The south wind arises in Summer; its sickness is located in the heart and there are disturbances in the chest and ribs. The west wind arises in Fall; its sickness is located in the lungs and disturbances arise at the shoulders and at the back ${ }^{49}$. Yoeli-Tlalim explains the importance of Tibetan 'irlung', also translated as 'wind' and closely associated to Chinese 'qi' and 'pneuma' in Greek ${ }^{62}$. These can also be associated to 'ruah' from Hebrew, which can also refer to wind, breath and soul63. Yoeli-Tlalim considers them to be crucial for investigating health and illness ${ }^{62}$. It can be associated with the fact that one of the meanings of 'to breathe out' is to die in Croatian, meaning breath is life. We are taking that concept into consideration as the notion translated with the word 'wind', without going further into the analysis of that concept itself which would require profound knowledge of the original language the book was written in, and also the culture it belongs to.

Disease in Huangdi Neijing is also described as a consequence of the seasons. DISEASE IS A SEASON: Thus sickness resulting from the atmosphere of Spring is located in the head. Sickness resulting from the atmosphere of Summer is located in the viscera. Sickness resulting from the atmosphere of Fall is located in the shoulders and the back; and sickness resulting from the atmosphere of Winter is located in the four members of the body ${ }^{49}$.
There are not many particular diseases as specific entities in Huangdi Neijing, in the sense that there is a recognizable pattern of symptoms that reoccur and have a name, but there are some, so there is mention of: numbness of the liver, numbness of the bones, numbness in the hands, numbness of the heart, numbness of the lungs, numbness of the kidneys; wind and convulsions, hot sick$n e s s^{49}$. There is also a certain classification of diseases, according to different parameters, so they can be light or grave, rare or frequent, stubborn or obedient diseases (depending on whether they respond to the treatment). The next two passages from the translation give us a view of the process of diagnosis and the overview of diseases:

To treat and to cure disease means to examine the body, the breath, the complexion, its glossiness or degree of moisture and the pulse, as to whether it is flourishing or deteriorating, and whether the disease is a recent one ${ }^{49}$.

One investigates the nine subdivisions separately and examines separately the trifling diseases and the grave diseases, the severe ailments and the lingering, penetrating) illnesses, the diseases with fevers and the diseases with chills, and those which are accompanied by falling down. ${ }^{49}$

As Magner states, the Nei Ching is a collection of sometimes contradictory ideas and interpretations forced into a supposedly integrated conceptual system ${ }^{50}$. The conceptual system in Huangdi Neijing is perfectly organized every season has a relation to disease, every viscera, complexion, pulse, etc. There is an order, a symetry in that system. Still, we can recognize some features that diseases have in common. First of all, it is clearly stated that medicine needs to prevent diseases. Treating a disease after it appears is compared to digging a well after a person became thirsty ${ }^{49}$. Also, people used to be healthy, there was less disease in the past, according to Yellow Emperor ${ }^{49}$. According to that, HEALTH IS NORMAL. One of the most prominent features of disease is that it is a change - a change in complexion, pulse, behavior, temperature, humidity and so on. It can be a loss of something, it can be an excess, but it is an imbalance (in regards to temperature and humidity). It can be a change because of a loss of an ability (sight, movement, breathing). It is also a loss of control, characterized by involuntary actions, like coughing. Diseases are visible changes on human body and they are transient in the sense that it is clearly visible when the change starts occuring and when it ends; whether in death, or in recovery.

\section{Hippocratic Corpus / Hippocratic Writings}

Greek medicine is considered to be the forerunner of modern medicine, for it was the Greek medicine that began the tradition of medicine as a rational, scientific system $^{50}$. To qoute Magner: In Western history, Hippocratic medicine is revered for its emphasis on the patient instead of the disease, observation rather than theory, respect for facts and experience rather than philosophical systems, "expectative therapy" (rather like "watchful waiting") as 
opposed to "active intervention," and the Hippocratic motto: "At least do no harm." Hippocratic Writings that medicine is invented for the sake of the sick ${ }^{54}$.

Contemporary medicine deals with diseases as entities, a reoccuring pattern of symptoms recognizable as a specific disease. In Hippocratic writings there are also many disease entities: ardent fevers, pneumonia, epidemic disease, common disease, peculiar diseases, diarrhea, dysentery, hepialus, chronic fevers in winter, epinyctis, hemorrhoids, pleurisy, peripneumonia, ophtalmia, maniacal affection, leucophlegmasia, oedema, hernia, varices and ulcers on legs, stone, disease of the kidneys, sciatica, strangury, catarrhs, sphacelus, coryza, consumption, hoarseness, coughs, insomnolency, empyema, abscesses, fistula, strong and continued headaches with fever, hard bladder and painful along with continued fever, acute pain of the ear, quinsy, erysipelas, erythema, paraplegia ${ }^{54}$. The term 'acute disease' also has its provinence in ancient Greek medicine. Acute diseases are pleurisy, pneumonia, phrenitis, lethargy, causus (ardent fever), continual fevers, dropsy (anasarca). There are also epidemic diseases, ones that come upon a lot of people at the same time. There are descriptions of such diseases, their symptoms, but they do not have names; they are translated as constitutions ${ }^{54}$.

In the Hippocratic writings $(\mathrm{HW})$ there are certain symptoms or states that appear before the onset of a disease. They signalize that a disease could happen, but they themselves are not disease. For instance, when a person is heavy and inactive, with the body weighed down and mind, too, slumbering, yawning, thirst, flatulence, tormina (severe stomach pain), diarrhea, great loss of strength, trembling, pallid eyes, thick urine, bitter mouth, bowels like they are hanging loose, thick urine, vertigo, lowness of spirit, insomnolency, disturbed dreams ${ }^{54}$. DISEASE IS A MULTI-STAGE PROCESS. Weakness is the beginning of the disease.

HW criticizes the notion from ancient medicine that disease is a result of too much heat or cold, or excessive dampness or dryness ${ }^{54}$. But, balance and temperance are important. Everything in moderation is recommended in HW. Also, HW recognizes the importance of continuity, for instance in the diet. Some of the states that anticipate a disease are the consequence of a disturbance in dietary habits $^{54}$. In the Chinese traditional medicine, overindulgence in food results in a disease ${ }^{49}$, but in $\mathrm{HW}$ any change in dietary habits can result in an altered state of the body and lead to a disease ${ }^{54}$. In Huangdi Neijing behavior has a more significant role than it does in HW. Any distancing from Tao, every overindulgence is a path to disease, but in $\mathrm{HW}$ the quality of the habits is not as important as in Huangdi Neijing, only the change. On the other hand, the third constitution of epidemic diseases is more likely to appear connected to a certain phenotype; smooth skin, black hair, and it can also be connected to behavior that lacks moderation and temperance ${ }^{54}$.

The other idea that is criticized in HW is the idea of the supernatural segments in disease, especially in the part dealing with the 'sacred disease'. DISEASE IS A NATURAL PROCESS. Diseases are the result of structures or powers. Powers are strong and intense juices and structures and conformations in man (broad to narrow, expanded, hard and round.... ${ }^{54}$. Greek medicine developed the doctrine of four humors, which means DISEASE IS AN IMBALANCE OF HUMORS - blood, phlegm, black bile, and yellow bile ${ }^{50}$.

Same as in Chinese medicine, HW stresses the importance of season and region. Physicians must consider seasons of the year, winds - hot and cold, peculiar winds, quality of the water, (when coming to a new city) locality - wind, sun, water, habits of the locals - eating, drinking, common diseases and peculiar ones. They should be able to know which epidemic diseases will hit the city. A physician must also be aware of the weather, and astrology can be of help, too ${ }^{54}$. DISEASE IS SEASONAL and DISEASE IS REGIONAL. In the Huangdi Neijing season is described as a cause of the disease, but in HW it is an element that helps with the diagnosis and prognosis, which was the most important for a physician's credibility ${ }^{50,54}$.

As already stated, disease in HW is a multi-staged process. It is important to know the meaing of symptoms. There are salutary asymptoms and there are those that suggest the prolongation of the disease or even death. As already mentioned, it is important to anticipate the outcome: prognosis ${ }^{54}$. In Huangdi Neijing there is no gradation of symptoms, they are numbered and it is not stressed that some might be more significant than others ${ }^{49}$, there are no salutary symptoms like in $\mathrm{HW}^{54}$. Also, in HW the meaning of a certain symptom is individual, context-dependent. So, if a person grinds his teeth, and it was not a habit this person had since childhood - it is a bad sign, also the changes in sleeping - time of day when the person sleeps, for instance ${ }^{54}$. Therefore, DISEASE IS CHANGE. In Huangdi Neijing disease is also a change, but in relation to general standards, there is no mention of an individual's specific state ${ }^{49}$. HW considers the general nature of all, and the peculiar nature of each individual ${ }^{54}$. DISEASE IS INDIVIDUAL. In HW, change can also refer to a change in color, consistence or frequency of excrement, urination or vomitting, for example ${ }^{54}$. In Neijing colors have corresponding elements, which is not the case in $\mathrm{HW}$, but there is a very clear metaphor LIVID IS DEATH in HW. When livid, complexion, fingers, vomitting or excrement signify death as the outcome ${ }^{54}$. An important factor in diagnosis is sleeping, together with the dreams. A position in which a person sleeps can uncover the location of pain. Sleeping at a different time of day than usual can be an omen of death, as can the fact that a person's eyes are not completely shut while sleeping or that their eyelids, nose and mouth are pale ${ }^{54}$. DISEASE IS A CHANGE IN SLEEPING.

Although there is a critique in HW concerning the hot and cold as causes of diseases, they are important when the whole body is not of the same temperature. It is a bad sign when there are parts that are hotter or colder than the rest of the body. It is also bad when a person is sweat- 
ing only in certain body regions, while it is good when the whole body sweats ${ }^{54}$. DISEASE IS UNEVENNESS.

The elements that must be considered when deciding is something a disease and which disease it is are: general nature of all, peculiar nature of each individual, season, the state of the heavens, the nature of each country; patient's habits, regimen, and pursuits, his conversation, manners, taciturnity, thoughts, sleep, or absence of sleep, and sometimes his dreams, his picking and scratching, his tears, the alvine discharges, urine, sputa, and vomitings, the changes of diseases from the one into the other, the deposits, the sweat, coldness, rigor, cough, sneezing, hiccup, respiration, eructation, flatulence, hemorrhages and hemorrhoids ${ }^{54}$.

Parts of HW that are about surgery, injuries, fractures and articulations are different than those about the disease because they are much more focused on healing and treatment. Prognosis and diagnosis are not stressed like when it comes to disease. When a disease appears, the physician must observe it and predict the outcome, and he must heal injuries and fractures. Although fractures and injuries can also be potentially dangerous for the human and lead to death, there is a clear distinction between them and diseases.

\section{Otok}

Before describing diseases, Lovretić names falinkehealth impairments. He lists speech disorders, problems with vision (strabismus, for example), limp and so on. Those are mostly congenital states and they were not treated. People with impairments were members of the community like others, there were no limitations for them ${ }^{55}$

Part of the text called [Bolesti] Diseases, is not long. It is a list of the diseases recognized by the community which Lovretic describes. There are two main categories of recognized diseases: external and internal ${ }^{55}$. Those are disease entities the same as in modern medicine, a set of symptom patterns which reoccur. They have names and they are not thoroughly described. It is obvious that they were so well known that they did not require any explanation.

External diseases are categorized in three groups. First one are injuries, second one are ulcers and wounds and the third one are skin diseases. The same division of diseases appears when he later talks about medication ${ }^{55}$. Some types of injuries that appear in the chapter about medications, do not appear in the chapter about diseases. However, the categories are the same: external/internal, and external have the same subdivision. We have considered everything mentioned in both chapters.

Firstly, injuries are blisters, animal bites, scars and burns. They are all visible, they all appear as a consequence of some external influence, mostly a short-term event, and they have a predictable course. Their location is the skin surface. DISEASE IS A CHANGE ON THE SKIN SURFACE.
Ulcers and wounds are sores on different locations on or under the skin. They encompass swellings, similar to abscesses; filled with pus, mouth sores, swollen lymph nodes, eye infections, eye pain, acne, periodontal pain, gangrene, skin infections ${ }^{55}$. The difference between ulcers and wounds and the injuries is that injuries have a completely definite recognizable cause. Ulcers and wounds are results of a process without a known or predictable cause. Injuries are inflicted from the outside, they are results of an external event visible on the surface of human body. Ulcers and wounds are also visible on the surface of the body but they come from the inside. They are results of an internal process. DISEASE IS AN INTERNAL PROCESS. They cause body discontinuity from the inside. Their cause is not as recognizable as the cause of injuries. The moment in which an injury happens and its cause are completely known, and it is not known when or why ulcers and wounds start forming (wound is used here as, for instance, gangrene, not a wound inflicted by some external factor).

The third form of external diseases are skin diseases. Those are hair loss and communicable diseases, such as scabies or verruca and also sexually transmitted diseases. This is the part that shows the greatest difference in relation to the two prior sources. There are epidemics as a whole chapter in HW. Epidemics are defined by the number of people who have the same disease. Infectious diseases are common knowledge in Otok, but that was not the case in China and Greece. There is the miasma theory because miasma is mentioned in the $\mathrm{HW}$ as contaminated air ${ }^{64}$. However, there was no awareness about pathogens as a cause of disease in ancient Greece. Skin diseases in Otok are visible changes on the skin which are the result of a contact with someone with the same symptoms, or an object that someone with the same symptoms touched. Lovretic writes about skin changes around the mouth that one gets after using a cup out of which someone infected drank earlier ${ }^{55}$. DISEASE IS A CHANGE ON THE SKIN. DISEASE IS A CHANGE ON A PART OF THE BODY. DISEASE IS TRANSMISSIBLE.

Internal diseases are headache, earache, runny nose (infectious), mouth pain, sore throat, dry throat, scratchy throat, runny nose with a cough, maxillary cramps in newborn causing their death, painful neck blood vessels, chest pain, incurable cough (tuberculosis), audible breathing problems, abdominal pain, cramps, bone pain, ankle pain, blood in the stool, leg cramp, shiver, shaking, bone spread, joint dislocation, sudden disease, fever, fire, twiching, febrile convulsions, chicken pox, measles, epilepsy, water disease (cardiovascular diseases) ${ }^{55}$. Internal diseases are defined as a sensation inside the body which is not usual, and it is mostly an ache, pain. The other feature of internal diseases are involuntary actions: coughing, twitching and so on. The metaphors and metonymies underlying this group are: DISEASE IS CHANGE (DISEASE IS CHANGE OF THE STATE OF THE WHOLE BODY), DISEASE IS CHANGE OF TEMPERATURE, DISEASE IS CHANGE IN BODILY FLUIDS, DISEASE 
IS PAIN, DISEASE IS AN INVOLUNTARY ACT, DISEASE IS LEAKAGE, DISEASE IS DRYNESS, DISEASE IS HOT, DISEASE IS COLD, DISEASE IS COUGHING, DISEASE IS CHANGE IN BREATHING.

Internal diseases can be situated in a certain location, but they can also occupy the whole body, which is not the case with external diseases. Therefore, chicken pox and measles are in this group and not with other communicable diseases (scabies, for instance) which are concentrated on a certain body part. The cause of internal diseases is not known.

Common feature of the diseases is that they are processes inherent to human body. They are a change in relation to the normal state of the body. When something is congenital, it is not considered to be a disease and it is not treated, which we can conclude according to the fact that health impairments are not listed as diseases. HW and Huangdi Neijing do not mention such states in the terms of diseases, either. Unlike them, diseases are a change to the normal state of a human body. Diseases have causes. Causes can be external - with predictable outcomes, for instance, heat will cause burns. External causes have visible symptoms on the surface of the body. Internal causes are not predictable. They can result with outcomes visible on the body, for example hemorrhoids, they can also cause involuntary actions of the body, or they are only manifested as internal sensations. DISEASE IS A LOSS OF CONTROL OVER THE BODY. DISEASE IS AN ABNORMAL STATE OF THE BODY. DISEASE IS PAIN.

\section{Conclusion}

All three analyzed sources have some common ideas about disease. First of all, disease is not a normal state for humans, it is transient. It is a change of a person's physical state caused by something. It is not congenital. In the modern WHO classification of diseases, there are categories: „Certain conditions originating in the perinatal period“ and „Congenital malformations, deformations and chromosomal abnormalities" ${ }^{44}$. We can conclude that even in the modern medicine, pathological congenital states which diminish the quality of life are not called diseases. Disease is a change in relation to prior state of a human organism. Diseases, therefore, have causes; certain behaviors or external factors that cause a change.

Hippocratic writtings and Huangdi Neijing recognize changes in behavior as important, although there is a difference between them. In Huangdi Neijing there is a standard for behavior which is generally accepted. Not behaving according to that standard can lead to disease and it can also be a symptom of disease. In Hippocratic Writings there is an emphasis on the individual state of a person before the disease. Symptoms must be interpreted in relation to a specific person. That is an element which does not appear in the other two sources: disease as an individual response of a certain human body or a person.

Injuries are caused by external factors, they are also a change of a person's physical state and they can lead to death, same as diseases, but they are divided from diseases in Otok and HW. They can also become the cause of a disease. The difference between a disease and an injury is in predictability and control. Disease is in the three analyzed sources connected to involuntary acts, such as coughing, belching and so on. Disease is a loss of control over the body and it is an unpredictable process. It can result in either recovery or death. Impairments and disabilities are also not disease, although they can be a change of a person's state if they occur during lifetime (as a result of an injury, for instance). Unlike diseases, impairments are not painful, although they do diminish the quality of life. Also, they mostly do not have fatal outcomes and they are predictable, like injuries.

We can conclude that when an unpredictable, transient change would happen in a person's physical state, caused by a certain behavior, an external factor or an unknown factor, with the outcome of recovery or death: people would think it is a disease in ancient China and Greece and in $19^{\text {th }}$ century Croatia. The most important attributes connected to disease in the analyzed sources are realted to body, change, process and control.

\section{R E F E R E N C E S}

1. LAKOFF G, Topics in Cognitive Science, 4 (2012) 773. doi:10.1111/ j.1756-8765.2012.01222.x. - 2. LAKOFF G, JOHNSON M, Metaphors we live by (Chicago and London, University of Chicago Press, 1980). - 3 . LAKOFF G, Front Neurol, 8 (2014) 958. - 4. DAMASIO AR, Philos Trans R Soc Lond B Biol Sci. 351 (1996) 1413. doi:10.1098/rstb.1996.0125]. — 5. KIVERSTEIN J, MILLER M, Front Neurol, 9 (2015) 237. - 6. CAMPBELL EJ, SCADDING JG, ROBERTS RS, BMJ, 2 (1979) 757-762. doi:10.1136/bmj.2.6193.757. - 7. GHEMBAZA MA, SENOUSSAOUI Y, TANI MK, MEGUENNI K, Curr Hypertens Rev. 10 (2014) 41. doi:10.2 174/157340211001141111160653. - 8. PRISTIANTY L, KURNIATI VL, HIDAYATI IR, J Basic Clin Physiol Pharmacol, 30 (2020)0321. doi:10.1515/jbcpp-2019-0321. - 9. MURPHY J, COSTER G, Drugs, 54 (1997) 797. doi:10.2165/00003495-199754060-00002. — 10. CHAURASIA RC, J Indian Med Assoc, 109 (2011) 339. - 11. HOMEDES N, UGALDE A, Bull Pan Am Health Organ, 28 (1994) 17. — 12. UMAKI TM, UMAKI MR, COBB CM, J Periodontol, 83 (2012) 395. doi:10.1902/ jop.2011.110344. - 13. CAMERON C, J Adv Nurs, 24 (1996) 244. doi:10.1046/j.1365-2648.1996.01993.x. - 14. NAM S, CHESLA C, STOTTS NA, KROON L, JANSON SL, Diabetes Res Clin Pract, 93 (2011) 1. doi:10.1016/j.diabres.2011.02.002. - 15. FADIMAN A, The spirit catches you and you fall down: a Hmong child, her American doctors, and the collision of two cultures (New York, Farrar, Straus, and Giroux, 1997). — 16. RAMIN B, Mcgill J Med, 10 (2007) 127. — 17. HEWLETT BS, EPELBOIN A, HEWLETT BL, FORMENTY P, Bull Soc Pathol Exot, 98 (2005) 230. - 18. FATOVIĆ-FERENCIĆ S, Croat Med J, 49 (2008) 709. doi:10.3325/cmj.2008.49.709. — 19. AIRD WC, J Thromb Haemost, 9 (2011) 118. doi:10.1111/j.1538-7836.2011.04312.x. — 20. PASIPOULARIDES A, J Appl Physiol (1985), 11 (2013) 1493. doi:10.1152/japplphysiol.00216.2013. — 21. MODELL H, CLIFF W, MICHAEL J, MCFARLAND J, WENDEROTH MP, WRIGHT A, Adv Physiol Educ, 39 (2015) 259. doi:10.1152/advan.00107.2015. — 22. BILLMAN GE, Front Physiol. 2020;11:200. doi:10.3389/fphys.2020.00200. - 23. FATOVIĆ-FERENČIĆ S, BUKLIJAŠ T, Coll Antropol, 24 (2000) 1. — 24. MINAIRE P, Bull World Health Organ, 70 (1992) 373. — 25. 
WIKMAN A, MARKLUND S, ALEXANDERSON K, J Epidemiol Community Health, 59 (2005) 450. doi:10.1136/jech.2004.025346. - 26 . BOYD KM, Med Humanit, 26 (2000) 9. doi:10.1136/mh.26.1.9. — 27. HOFMANN B, J Med Philos, 27 (2002) 651. doi:10.1076/ jmep.27.6.651.13793. — 28. SINGER M, BAER HA, Introducing medical anthropology : a discipline in action (AltaMira Press, 2007). - 29. FOSTER GM, ANDERSON BG, Medical anthropology (NewYork, John Wiley and Sons, 1978). - 30. TAYLOR JR, Linguistic categorization (Oxford, University Press, 2009). - 31. OMONZEJELE PF, EXPLORE, 42 (2008) 120. doi:10.1016/j.explore.2007.12.001. - 32. BUKOVČAN T, Etnoloska Tribina, 43 (2013) 90. - 33. TAYLOR JS, Acad Med, 78/6 (2003) 555. doi: 10.1097/00001888-200306000-00003. - 34. ROGERS WA, WALK ER MJ, J Med Philos, 42 (2017) 405. doi:10.1093/jmp/jhx010. — 35. LAU RR, HARTMAN KA, Health Psychol, 2 (1983) 167. doi:10.1037/0278. 6133.2.2.167. - 36. COHEN H, Proc R Soc Med, 48 (1955) 155. - 37. KOVÁCS J, Med Health Care Philos, 1 (1998) 31. doi:10.1023/a:1009981721055. - 38. NORDENFELT L, Med Health Care Philos, 10 (2007) 5. doi:10.1007/s11019-006-9017-3. - 39. MORDACCI R, SOBEL R, The Hastings Center Report, 28 (1998) 34. doi:10.2307/3527973. - 40. KOTTOW MH, Med Hypotheses, 6 (1980) 209. doi:10.1016/0306-9877(80)90085-7. - 41. BOORSE C, Philos Sci, 44 (1977) 542. - 42. HODGKIN P, BMJ, 291 (1985) 1820. doi:10.1136/ bmj.291.6511.1820. - 43. MIHIĆ D, MIRAT J, VČEV A, (Eds) Interna medicina (Osijek, Medicinski fakultet Osijek, 2021). - 44. WHO. International Statistical Classification of Diseases and Related Health Problems (ICD), 10th Revision, Vol.2. https://www.who.int/classifications/icd/ ICD10Volume2_en_2010.pdf. - 45. WHO, Official Records of WHO, no. 2 (United Nations and World Health Organization New York \& Geneva, 1946. - 46. SHIM JM, Asia Pac J Public Health, 28 (2016) 51. doi:10.1177/1010539515613411. — 47. SELIN H, Medicine Across Cultures: History and Practice of Medicine in Non-Western Cultures (Dordrecht; Boston : Kluwer Academic Publishers, 2003). - 48. CAVALIERI S, ROTOLI M, Recenti Prog Med, 88 (1997) 541. - 49. VEITH I, The Yellow Emperor's classic of medicine = Huan Ti nei ching su wen (University of California Press, 1972). - 50. MAGNER LN, A history of medicine (Marcel Dekker, 2005). - 51. WATTS S, Disease and Medicine in World History. Disease and Medicine in World History (London, Routledge, 2003). doi:10.4324/9780203987896. — 52. GLESINGER L, Povijest medicine (Zagreb, Školska knjiga, 1978). — 53. YAPIJAKIS C, In Vivo, 23 (2009) 507. - 54. HIPPOCRATES, ADAMS F, BROCK AJ, GALEN, Hippocratic writings (Chicago, Encyclopaedia Britannica, 1989). - 55. LOVRETIĆ J, Otok (Vinkovci, Privlačica, 1990). - 56. SVIRAC M, Etnološka tribina 13 (1984) 127. - 57. GARDAŠ M, ČANDRLIĆ S, REPIĆ M, Zbornik Pravnog fakulteta Sveučilišta u Rijeci, 41 (2020) 531. doi:10.30925/zpfsr.41.2.5. - 58. PANTHER KU, THORNBURG LL, Synthesis philosophica, 32 (2017) 271. — 59. LAKOFF G, Cognitive models and prototype theory. In NEISSER U (Ed), Concepts and conceptual development: Ecological and intellectual factors in categorization (Cambridge University Press, 1987). - 60. SADEGHZADEH K, J Med Philos, 25 (2000) 605. doi: 10.1076/03605310(200010)25:5;1-w;ft605. — 61. SADEGH-ZADEH K, J Med Philos, 33 (2008) 106. doi:10.1093/jmp/jhn004. - 62. YOELI-TLALIM R, Stud Hist Philos Biol Biomed Sci, 41 (2010) 318. doi:10.1016/j.shpsc.2010.10.005. - 63. STAPLES WE, AJSL, 44 (1928) 145. - 64 JOUANNA J, ALLIES N. Air, Miasma and Contagion in the Time of Hippocrates and the Survival of Miasmas in Post-Hippocratic Medicine (Rufus of Ephesus, Galen and Palladius). In: VAN DER EIJK P (Ed): Greek Medicine from Hippocrates to Galen. (Brill, Leiden-Boston, 2012).

\section{Raguž}

Faculty of Medicine, Josip Juraj Strossmayer University, Josipa Huttlera 4, 31000 Osijek, Croatia e-mail: marija.raguz@mefos.hr

\section{TRI PREDMODERNA KONCEPTA BOLESTI}

\section{S A Ž E T A K}

Koncepti zdravalja i bolesti utječu na učinkovitost medicinskih sustava. Trenutno ne postoje općeprihvaćene definicije zdravlja i bolesti, unatoč tome što su mnoga istraživanja nastojala prepoznati njihovu bit. Većina dostupnih istraživanja koncepta bolesti oslanja se na koncept bolesti moderne medicine utemeljene na dokazima. Ti se koncepti zdravlja i bolesti razlikuju od koncepata opće populacije. U ovome istraživanju koristimo kognitivnolignvistički pristup konceptima, uzimajući u obzir način na koji ljudski um obrađuje stvarnost koja ga okružuje. Ti su procesi utemeljeni na univerzalnim načelima zbog utjelovljenosti ljudskoga kognitivnog sustava. U skladu s time, koncepti su do određene razine neovisni o vremenu i kulturi. Odabrali smo tri predmoderna izvora s dovoljno podataka o bolesti kako bi se moglo ustvrditi postoje li sličnosti u onome što oni podrazumijevaju pod bolešću. Prvi je izvor "Huang Di Nei Čing", dio "Suven", iz drevne kineske medicine, drugi je "Hipokratski rukopisi" iz antičke Grčke, a treći je "Otok" Josipa Lovretića iz istočne Hrvatske, iz 19. stoljeća. Djela su produkti vrlo različitih kultura i povijesnih razdoblja. Usporedbom obilježja povezanih s bolešću u sva tri izvora, kao ključne zajedničke atribute povezane uz bolest prepoznali smo elemente koji se tiču tijela, promjene, procesa i kontrole. 
